\title{
Designing and validation of genus-specific primers for human gut flora study
}

\author{
Rani Rekha \\ School of Life Sciences \\ Jawaharlal Nehru University \\ New Delhi 110067 \\ India \\ Tel: 9101126704516 \\ Fax: 9101126717580 \\ E-mail: rekhs2004garg@gmail.com
Moshahid Alam Rizvi
Department of Biosciences
Jamia Millia Islamia
New Delhi 110025
India
E-mail: rizvi_ma@yahoo.com \\ Paul Jaishree* \\ School of Life Sciences \\ Jawaharlal Nehru University \\ New Delhi 110067 \\ India \\ Tel: 9101126704516 \\ Fax: 9101126717580 \\ E-mail:.jpaul33@hotmail.com
}

Financial support: University Grant Commission, New Delhi, India.

Keywords: 16S rRNA based primers, anaerobic bacteria; diarrhoea patient, polymerase chain reaction.

Abbreviations:
AAD: Antibiotic Associated Diarrhoea
BLAST: Basic Local Alignment Search Tool
IMTECH: Institute of Microbial Technology
MTCC: Microbial Type Culture Collection Center
PCR: polymerase chain reaction
RFLP: Restriction Fragment Length Polymorphism
rRNA: ribosomal ribonucleic acid
U: Units

The aim of this study, was to design and validate $16 \mathrm{~S}$ rRNA targeted oligonucleotide genus specific primers for amplifying the predominant members of gut flora using polymerase chain reaction. Primers were validated against human faecal samples. Gut flora of a normal individual was compared with that of two diseased individuals. Our observations showed that the genera Lactobacillus, Bacteroides, Peptococcus, Bifidobacterium, and $E$. coli were invariably present in all studied subjects however, the absence of butyrate producing bacteria Ruminococcus and Peptostreptococcus were significant. Presence of the members of the genus, Campylobacter in both the diseased samples were also unusual.

The normal gut biota represents a complex microbial ecosystem (the "enterome") that plays a crucial role in homeostasis of the gastrointestinal tract (McCracken and Lorenz, 2001). Human gut microflora is comprised of more than 400 bacterial species. It has been indicated that in normal adults, strictly anaerobic bacteria form $90 \%$ of the predominant organisms and $10 \%$ of flora are aerobic in nature (Salminen et al. 1995). The predominant anaerobic members of endogenous human gastrointestinal tract belong to the following genera- Bacteroides, Bifidobacterium, Clostridium, Fusobacterium,

*Corresponding author 
Ruminococcus, Peptostreptococcus and Peptococcus.

The traditional methods for identifying faecal bacteria include various culture techniques, bacteriological isolations, biochemical tests, morphological examination, and analysis of volatile and non-volatile acid production. These methods have limitations since they are time consuming as well as unable to present the complete status of flora. However application of molecular techniques such as PCR allows the rapid detection of a wide range of bacterial species including both cultivable and noncultivable microorganisms (Carrino and Lee, 1995; Dutta et al. 2001). The $16 \mathrm{~S}$ rRNA molecule consists of a mosaic of highly conserved, semi-conserved and highly variable regions, and has become an important tool in molecular phylogeny studies (Woese, 1987). Since the rRNAs differ along their lengths in relative sequence conservation, the targeting of regions of greater or lesser conservation offers exquisite control of probes specificity. Among these regions conserved sequences in all species for a particular genus can be selected as primer sequence; flanking the variable regions. A rapidly accumulating $16 \mathrm{~S}$ rRNA database facilitated designing of species or group-specific oligonucleotide probes that can be used for the rapid enumeration of anaerobes, independent of cultivation, following shifts in microbial communities to be accurately monitored (Suau et al. 1999).

The human gut microbiota composition may get disturbed under certain circumstances like diarrhoeal condition that may be caused due to infection or antibiotic intake. Antibiotic associated diarrhoea (AAD) may be due to overgrowth of Clostridium difficile (Bartlett, 2002). Another possible mechanism is the loss of beneficial metabolic activities of intestinal microbes (Dunne, 2001). Global changes in the composition and quantity of the gut microbiota (even in the absence of overgrowth by pathogenic microorganisms) can result in perturbations of global colonic metabolism that lead to AAD (Högenauer et al. 1998).

In the present study, genus specific primers were designed and validated using faecal samples collected from one healthy and two diarrhoeal patients.

\section{MATERIALS AND METHODS}

\section{Designing and validation of primers}

Members of predominating gut bacteria were short listed from the literature (Salminen et al. 1995). 16S rRNA sequences of maximum species of a specific genus encountered in the human gut were downloaded from the EMBL database as well as Genbank.

In order to avoid any non-specific amplification of nontargeted genera, the sequences of all the genera fetched from the database were subjected to CLUSTALX (Jeanmougin et al. 1998) programme. The blocks of hyper variable regions showing variations among genera were picked up. These sequences were then subjected to second round of alignment where the maximum number of species belonging a genus was aligned and the regions showing conservations were selected as genus specific primers. Genbank program BLAST (Altschul et al. 1990) was used to further ensure that the proposed primers were complementary with the target species and not with the non-targeted one.

Six different primer sets were designed to differentiate following major anaerobic genera (normally encountered in human gut)- Bifidobacterium (Bif), Ruminococcus (Rum), Lactobacillus (Lacb), Campylobacter (Camp), Peptococcus (Pep), and Clostridium (Clos). Primers for Bacteroides (Bacto) and Peptostreptococcus productus (PSP) were obtained from the published work (Menaja et al. 1996; Wang et al. 1996). For Staphylococcus aureus, primers (mecA-1 and mecA-2) based on methicillin resistant gene were used (Louie et al. 2002). Primer set used for the detection of E. coli was based on the malB promoter gene (Wang et al. 1996).

Table 1 lists the sequences of the primers designed for each genus, their nucleotide position with respect to E. coli $16 \mathrm{~S}$ rRNA, size of the PCR product and the annealing temperature value for each primer set, used in this study. The nomenclature for the targeted primers was selected following the OPD database (Alm et al. 1996). All the primers were commercially synthesized from Microsynth (GMBH, Switzerland).

\section{Standard cultures used to ensure primers specificity}

Lyophilized cultures of following bacterial strains were procured from the Microbial Type Culture Collection Center (MTCC) located at the Institute of Microbial Technology (IMTECH) Chandigarh, India. They were, Bacillus subtilis (MTCC 121), Staphylococcus aureus (MTCC 740), Lactobacillus cassie (MTCC 1423), Enterococcus faecalis (MTCC 439), Escherichia coli (MTCC 1302), Salmonella infantis (MTCC 1107), Klebsiella pneumoniae (MTCC 432) and Pseudomonas aeruginosa (MTCC 741). All reference strains were cultivated as recommended by MTTC. Genomic DNA was isolated from the lyophilized cultures of bacterial strains using Sarkosyl- Proteinase K method (Hancock, 2002). Genomic DNA of Bacteroides fragilis (ATCC 25285D) was provided by the Microbiology Laboratory, All India Institute of Medical Sciences, New Delhi, India.

\section{Clinical status of subjects}

Samples were collected from one healthy and two diarrhoeal subjects belonging to adult age group. Sample was collected from healthy individual (an adult female; NF) who didn't consume any antibiotic for a period of six months, prior to sample collection and was not having any 

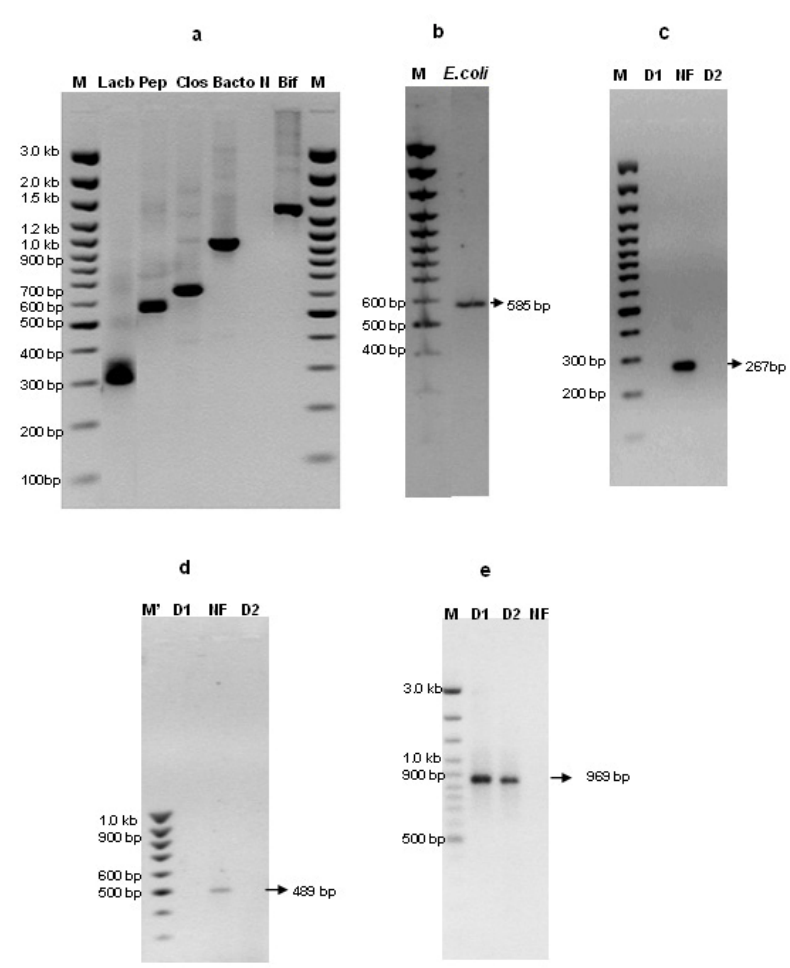

Figure 1. Validation of primers used. (a) The PCR products amplified with genus-specific primers for genera Lacb, Pep, Clos, Bacto and Bif using healthy individual's template DNA. (b) PCR product with E. coli -specific primers using healthy individual's template DNA. (c) PCR products with PSP specific primers for all three subjects.

(d) PCR products with Rum specific primers for all three subjects.

(e) PCR products with Camp specific primers for all three subjects. Details of primers from $16 \mathrm{~S}$ rDNA were designed for various bacterial species (abbreviated on the top of each lane) are represented in Table 1. Details of the subjects NF, D1 and D2 are mentioned in Materials and methods. $M$ and $M$ ' represents molecular markers of $100 \mathrm{bp}$ plus and $100 \mathrm{bp}$ (MBI fermentas) $\mathrm{N}=$ No DNA template.

episode of clinical disorder. Among diseased individuals, sample D1 was collected from an old age female suffering from bronchitis infection and was prescribed augmentin for 8 days $(875 \mathrm{mg} / 12 \mathrm{hrs})$. Patient had no history of chronic gastrointestinal disease and did not consume any antibiotics at least for a year. On the third day of antibiotic intake, patient noted the onset of bulky, loose stools. The patient denied of any abdominal pain or fever. The second diarrhoea patient; an adult male (D2) was suffering from acute giardiasis. Giardiasis patient was on flagyl treatment for three days, when the sample was collected. All three individuals were consuming regular vegetarian diet.

\section{Sample collection}

Faecal samples collected in sterile vials were transported to laboratory within $2 \mathrm{hrs}$ after collection and immediately frozen at $-20^{\circ} \mathrm{C}$ for DNA isolation purpose.

\section{Morphological and microscopic observations}

To identify ova and cysts of the intestinal parasite in giardiasis patient's faecal sample, wet mount preparations were prepared in normal saline and stained with Lugol's iodine for cysts.

\section{DNA isolation}

DNA isolation from frozen faecal samples was done using Qiagen stool DNA mini kit; Qiagen, according to the instructions of the manufacturer. $180 \mathrm{mg}$ of sample was used and concentration of DNA was determined by eye estimation on $0.6 \%$ agarose gel electrophoresis.

\section{Testing of primers for PCR amplification}

PCR was performed in Tech gene, thermal cycler (Nugen Scientific, USA). PCR was performed in $20 \mu \mathrm{l}$ (final volume) containing $1 \mathrm{X}$ of $10 \mathrm{X}$ PCR buffer (containing 750 $\mathrm{mM}$ Tris- $\mathrm{HCl}\left(\mathrm{pH} 8.8\right.$ at $\left.25^{\circ} \mathrm{C}\right), 200 \mathrm{mM}\left(\mathrm{NH}_{4}\right)_{2} \mathrm{SO}_{4}, 0.1 \%$ Tween-20), $2 \mathrm{mM}$ of each dNTP, $2 \mathrm{mM} \mathrm{MgCl}$ (except for Lactobacillus, where $1.5 \mathrm{mM} \mathrm{MgCl}_{2}$ was used), $20 \mathrm{pmol}$ of each primer and $2 \mathrm{U}$ of Taq DNA polymerase (MBI Fermentas, USA) and $2.5 \mu \mathrm{l}$ of template DNA (Faecal sample DNA). The amplification conditions were; one cycle of $94^{\circ} \mathrm{C}$ for 5 min followed by 30 cycles of $94^{\circ} \mathrm{C}$ for $30 \mathrm{sec}$, annealing (annealing temperatures mentioned in Table 1) for $1 \mathrm{~min}, 72^{\circ} \mathrm{C}$ for $1 \mathrm{~min}$, final extension at $72^{\circ} \mathrm{C}$ for $8 \mathrm{~min}$ and finally cool down to $4^{\circ} \mathrm{C}$. PCR products were checked for expected sizes on $1.5 \%$ agarose gel by loading $20 \mu \mathrm{l}$ of the PCR reaction along with molecular marker of 100 bp ladder plus (MBI Fermentas, USA). Gel run was carried out for 3-4 hrs. Sizes of various amplicons generated by genus specific primers were checked as per Table 1. DNA isolated from the above mentioned pure strains were used as controls ( $\sim 80 \mathrm{ng}$ genomic DNA) for the subsequent PCR experiments.

\section{Validation of primers specificity}

PCR products were amplified using faecal DNA from healthy individual using genus specific primers. Later these products were purified using Qiagen gel extraction kit and cloned into pGEMT ${ }^{\circledR}$ - easy vector (Promega co., Madison, USA). Similarly PCR product for Campylobacter amplified from diseased individual's sample DNA was purified and cloned into pGEMT-easy vector. The cloned products were sequenced and analyzed using NCBI BLASTN program. Sequences were submitted to EMBL nucleotide database (WEBIN). These cloned products were used as control DNA when PCR reactions were carried out with diseased individuals. Each PCR reaction was repeated thrice for all samples to confirm the reproducibility of the technique.

\section{RESULTS}

Analysis of PCR products generated using the genus specific primers 
In order to test specificity of the primers (Table 1) target and non- target DNA were used as positive and negative controls with each PCR reactions. In order to further authenticate primers, amplicons generated using genus specific primers for healthy individual and Campylobacter for diseased one (Figure 1) were cloned and sequenced. Primers used for amplification of targeted genera (genomic DNA of pure strains) worked well whereas, no amplification was observed with non- targeted genera and non-targeted clones DNA.

The accession numbers were: AM042696 (Bacteroides vulgatus partial 16S rRNA gene), AM042697 (Uncultured Clostridium sp. partial 16S rRNA gene), AM042698
(Uncultured Bifidobacterium sp. partial 16S rRNA gene), AM042699 (Campylobacter coli partial 16S rRNA gene), AM042700 (Peptococcus sp. RR-2005 species partial 16S rRNA gene), AM042701 (Lactobacillus acidophilus partial 16S rRNA gene), AM117587 (Peptostreptococcus productus partial 16S rRNA gene) and AM117597 (Ruminococcus partial 16S rRNA gene). The species names, in given accession numbers have been mentioned on the basis of BLAST results showing highest hits with particular species.

\section{PCR results}

DNA isolation using Qiagen kit yielded DNA of high

Table 1. Positions of genus specific primer sequences with respect to E. coli $16 \mathrm{~S}$ rRNA.

\begin{tabular}{|c|c|c|c|c|}
\hline Genus & Primer Sequence & $\begin{array}{l}\text { Primer Position } \\
\text { vs E. coli } 16 S \text { rRNA† }\end{array}$ & $\begin{array}{c}\text { PCR } \\
\text { Product }\end{array}$ & $\begin{array}{l}\text { Annealing } \\
\text { Tempł }\end{array}$ \\
\hline Bacteroides & $\begin{array}{l}\text { GGGGTTCTGAGAGGAAG } \\
\text { ACCCCCCATTGTACCAC }\end{array}$ & $\begin{array}{l}\text { S-G- Bacto- 0297- S- } 17 \\
\text { S-G- Bacto-1245- A- } 17\end{array}$ & $950 \mathrm{bp}$ & 52.0 \\
\hline Bifidobacterium & $\begin{array}{l}\text { CGCTGGCGGCGTGCTTAACACAT } \\
\text { CGCGATTACTAGCGACTCCGCCTTCA }\end{array}$ & $\begin{array}{l}\text { S-G- Bif- 0008- S- } 23 \\
\text { S-G- Bif- } 1306-\text { b- A- } 26\end{array}$ & $1300 \mathrm{bp}$ & 60.0 \\
\hline Lactobacillus & $\begin{array}{l}\text { TGCCTAATACATGCAAGTCGA } \\
\text { GTTTGGGCCGTGTCTCAGT }\end{array}$ & $\begin{array}{l}\text { S-G-Lacb-0018-S-21 } \\
\text { S-G-Lacb-336-A-19 }\end{array}$ & $318 \mathrm{bp}$ & 52.0 \\
\hline Ruminococcus & $\begin{array}{l}\text { CCTCTGACCGCTCTTTAATCGGAGCTTTCCTTC } \\
\text { CCAGTTATCGGTCCCACCTTCGGCAGCT }\end{array}$ & $\begin{array}{l}\text { S-G-Rum-0998-S-33 } \\
\text { S-G-Rum-1447-A-28 }\end{array}$ & $482 \mathrm{bp}$ & 61.0 \\
\hline $\begin{array}{l}\text { Peptostreptococcus } \\
\text { productus }\end{array}$ & $\begin{array}{l}\text { AACTCCGGTGGTATCAGATG } \\
\text { GGGGCTTCTGAGTCAGGTA }\end{array}$ & $\begin{array}{l}\text { S-G-PSP-0212-S-20 } \\
\text { S-G-PSP-0503-A-19 }\end{array}$ & $270 \mathrm{bp}$ & 51.0 \\
\hline Peptococcus & $\begin{array}{l}\text { GGTGCCGCAGTAAACACAATAAGT } \\
\text { AAGGCCCGGGAACGTATTCA }\end{array}$ & $\begin{array}{l}\text { S-G-Pep-0830-S-24 } \\
\text { S-G-Pep-1369-A-20 }\end{array}$ & $539 \mathrm{bp}$ & 53.0 \\
\hline Clostridium & $\begin{array}{l}\text { CTCAACTTGGGTGCTGCATTT } \\
\text { ATTGTAGTACGTGTGTAGCCC }\end{array}$ & $\begin{array}{l}\text { S-G-Clos-0586-S-21 } \\
\text { S-G-Clos-1205-A-20 }\end{array}$ & $619 \mathrm{bp}$ & 53.0 \\
\hline Campylobacter & $\begin{array}{l}\text { AGGGAATATTGCGCAATGGGGGAAA } \\
\text { TTACTAGCGATTCCGGCTTCATGC }\end{array}$ & $\begin{array}{l}\text { S-G-Camp-0466-S-25 } \\
\text { S-G-Camp-1435-A-24 }\end{array}$ & 969 bp & 55.0 \\
\hline E. coli & $\begin{array}{l}\text { ECO-1 GACCTCGGTTTAGTTCACAGA } \\
\text { ECO-2 CACACGCTGACGCTGACCA }\end{array}$ & Mal B promoter gene & $585 \mathrm{bp}$ & 53.0 \\
\hline $\begin{array}{l}\text { Staphylococcus } \\
\text { aureus }\end{array}$ & $\begin{array}{l}\text { mecA-1 AAAATCGATGGTAAAGGTTGGC } \\
\text { mecA-2 AGTTCTGCAGTACCGGATTTGC }\end{array}$ & $\begin{array}{l}\text { Methicillin resistance } \\
\text { gene }\end{array}$ & $533 \mathrm{bp}$ & 51.0 \\
\hline
\end{tabular}

† Primer positions are represented according to the OPD nomenclature (Alm et al. 1996). As per nomenclature; ' $S$ ': Small subunit rRNA, A hyphen (S-). Each character or group of characters in the primer name is set off with a hyphen to facilitate computer -aided manipulations. G: Genus; A: antisense template strand; S; DNA sense strand; 4 digit number in the middle represents the position of the primer with respect to $E$. coli and the last two digit number depicts the number of nucleotides present in the primer; e.g. (S-G-Bif-1306-A-26). Bacto: Bacteroides; Bif: Bifidobacterium; Rum: Ruminococcus; Lacb: Lactobacillus; Pep: Peptoccoccus; PSP: Peptostreptococcus productus; Clos: Clostridium. Primer sets for Bacto (Menaja et al. 1996); PSP (Wang et al. 1996); E. coli (Wang et al. 1996); and S. aureus (Louie et al. 2002) used in the present study are cited in the literature.

‡: Annealing temperatures are based on standardized conditions. 
purity grade suitable for PCR reaction and concentration of DNA was approximately $50 \mathrm{ng} / \mu \mathrm{l}$. Volume of template DNA used $(2.5 \mu \mathrm{l} ; \sim 62 \mathrm{ng})$ worked fine for PCR amplification. Comparison of PCR results for all three samples showed that the genera Lactobacillus, Bacteroides, Peptococcus, Bifidobacterium, and E. coli were invariably present in all subjects. However, the two genera, Ruminococcus and Peptostreptococcus were absent in the diseased subjects (Figure 1c and Figure 1d). Clostridium was absent in the antibiotic associated diarrhoea patient (D1). Interestingly, Campylobacter was present in both the diseased individuals while absent in healthy subject (Figure 1e). No amplicon was observed in any samples for methicillin resistant gene specific primers $(m e c \mathrm{~A}-1$ and mecA-2) used for detecting methicillin resistant Staphylococcus aureus strains.

\section{DISCUSSION}

The microbiota of the gastrointestinal tract of humans needs to be studied extensively because of the role played by gut bacteria both in the maintenance of gut homeostasis during healthy and disease conditions. Analysis of bacteria based on 16S rRNA primers is a sensitive and specific technique to identify gut flora that are difficult to cultivate. The reliability of the results is determined mainly by the specificity of the selected primers and experimental conditions. Among the 16S rRNA sequence based genus specific primers tested for BLASTN analysis, Bacteroides specific primers showed partial homology with Streptomyces, Cytophagals that are not inhabitants of human intestine. No homology was observed with any nontargeted genera for Bifidobacterium specific primers. Similarly other genus specific primers showed partial homology with Marichromatium purpuratum, Roseospirillum parvum and Thiomicrospira species that are also not encountered in a healthy human gut. Identification of closely related members of Enterobacteriaceae, for example, Shigella spp. and E. coli, is difficult to achieve using molecular probes since specific primers are difficult to design from 16SrRNA region (Christense et al. 1998). We have used mal B promoter gene sequence based primer set for $E$. coli detection (Wang et al.1996).

It is advantageous to use genus specific primers since it encompasses maximum number of species of a genus. Using RFLP technique for single PCR product, species differentiation can be accomplished for a genus along with the observation of variations, if any.

Primers used for the PCR reaction showed specificity for targeted genera. The sequences obtained from the cloned PCR products were subjected to BLAST analysis for confirming the specific genus. These clones were further used as appropriate controls.

An interesting observation in this study was the absence of Ruminococcus and Peptostreptococcus in the diseased samples whereas they were present in healthy individual.
Both the organisms are well-known butyrate -producing bacteria (Schwiertz et al. 2002, Wilson et al. 2000), which is a preferred energy source for colonic epithelial cells, and is thought to play an important role in maintaining colonic health in humans (Barcenilla et al. 2000). Clostridium was absent in old age female diarrhoea patient. There are reports indicating loss of normal resident flora due to antibiotic intake in diarrhoea and other infectious diseases (Wang et al. 2002; Tanaka et al. 2005). Loss of these bacteria due to antibiotic treatment can lead to increased amounts of carbohydrate in the colonic lumen, leading to an osmotic diarrhea. Augmentin (taken by D1, old age AAD patient) contains amoxicillin which is a broad spectrum drug used against bacterial infection (Bartlett, 2002). Our results for AAD patient also support the study by Young and Schmidt (2004) where loss of Clostridia cluster IV was observed due to intake of Amoxicillin. The drug Flagyl (metronidazole) used for giardiasis patient (D2) treatment is again a broad spectrum drug effective against protozoa and anaerobic bacteria (Muller, 1983). This may be responsible for the absence of the above flora in the giardiasis patient.

Presence of the members of Enterobacteriaceae e.g. E. coli as observed by us both in healthy and in diseased conditions has been reported earlier by Young and Schmidt (2004). This indicates that these members are rather stable even in diseased conditions.

In order to check if any of these patients acquired nosocomial infection due to Staphylococcus aureus, PCR was performed using mecA primer set. No methicillin resistant strains of Staphylococcus aureus was observed in any of the sample studied. Presence of Campylobacter in diarrhoeal subjects supported the earlier studies (Haque et al. 2003) showing chances of mixed infection in giardiasis patients. Our results indicated that both the patients suffering from diarrhoea were probably more prone to mixed infections. Our results show that Lactobacillus, Bacteroides, Peptococcus and Bifidobacterium were more stable flora and did not alter in diarrhoea conditions. However, due to lack of quantitative PCR data, it is difficult to comment on any change in titer of a specific genus due to diseased condition. Loss of predominant beneficial butyrate producing bacteria in diarrhoea conditions along with the presence of pathogenic genus Campylobacter was important observation.

Through this study we were able to design and validate genus specific primers and use them as molecular probes for PCR based detection of important gut bacteria in faecal samples. Observations made here, are preliminary ones, therefore whether the variation in flora is due to physiological status cannot be concluded out of the limited number of the samples analyzed. More number of samples, in each category needs to be analyzed for comparing gut flora profile between healthy and diseased individuals. 


\section{REFERENCES}

ALM, Elizabeth Wheeler; OERTHER, Daniel B.; LARSEN, Niels; STAHL, David A. and RASKIN, Lutgarde. The oligonucleotide probe database. Applied and Environmental Microbiology, October 1996, vol. 62, no. 10 , p. 3557-3559.

ALTSCHUL, Stephen F.; GISH, Warren; MILLER, Webb; MEYERS, Eugene W. and LIPMAN, David J. Basic local alignment search tool. Journal of Molecular Biology, October 1990, vol. 215, no. 3, p. 403-410.

BARCENILLA, Adela; PRYDE, Susan E.; MARTIN, Jennifer C.; DUNCAN, Sylvia H.; STEWART, Colin S.; HENDERSON, C. and FLINT, Harry J. Phylogenetic relationships of butyrate-producing bacteria from the human gut. Applied and Environmental Microbiology, April 2000, vol. 66, no. 4, p.1654-1661.

BARTLETT, John G. Antibiotic-associated diarrhea. The New England Journal of Medicine, January 2002, vol. 346, no. 5, p. 334-339.

CARRINO, John J. and LEE, Helen H. Nucleic acid amplification methods. Journal of Microbiological Methods, July 1995, vol. 23, no. 1, p. 3-20.

CHRISTENSE, H.; NORDENTOFT, S. and OLSEN, J.E. Phylogenetic relationships of Salmonella based on rRNA sequences. International Journal of Systematic Bacteriology, April 1998, vol. 48, no. 2, p. 605-610.

HANCOCK LABORATORY METHODS. Chromosomal DNA Isolation [online]. University of British Columbia [cited June 2002]. Available from Internet: http://www.cmdr.ubc.ca/bobh/showmethod.php?methodid= 15

DUNNE, Colum. Adaptation of bacteria to the intestinal niche: probiotics and gut disorder. Inflammatory Bowel Disease, May 2001, vol. 7, no. 2, p. 136-145.

DUTTA, Shanta; CHATTERJEE, A.; DUTTA, P.; RAJENDRAN, K.; ROY, S.; PRAMANIK, K.C. and BHATTACHARYA, S.K. Sensitivity and performance characteristics of a direct PCR with stool samples in comparison to conventional techniques for diagnosis of Shigella and enteroinvasive Escherichia coli infection in children with acute diarrhea in Calcutta, India. Journal of Medical Microbiology, August 2001, vol. 50, no. 8, p. 667674.

HAQUE, Rashidul; MONDAL, Dinesh; KIRKPATRICK, Beth D.; AKTHER, Selim; FARR, Barry M.; SACK, R. and BRADLEYAND PETRI, William A. Jr. Epidemiologic and clinical characteristics of acute diarrhea with emphasis on Entamoeba histolytica infections in preschool children in an urban slum of Dhaka, Bangladesh. The American
Journal of Tropical Medicine and Hygiene, October 2003, vol. 69 , no. 4, p. 398-405.

HÖGENAUER, Christoph; HAMMER, Heinz F.; KREJS, Guenter J. and REISINGER, Emil C. Mechanisms and management of antibiotic-associated diarrhea. Clinical Infectious Diseases, October 1998, vol. 27, no. 4, p. 702 710.

JEANMOUGIN, François; THOMPSON, Julie D.; GOUY, Manolo; HIGGINS, Desmond G. and GIBSON, Toby J. Multiple sequence alignment with Clustal X. Trends in Biochemical Science, October 1998, vol. 23, no. 10, p. 403405.

LOUIE, L.; GOODFELLOW, J.; MATHIEU, P.; GLATT, A.; LOUIE, M. and SIMOR, A.E. Rapid detection of methicillin-resistant Staphylococci from blood culture bottles by using a multiplex PCR assay. Journal of Clinical Microbiology, August 2002, vol. 40, no. 8, p. 2786-2790.

MENAJA, J.A.G.F.; SIMOES, F.; SOUSA, A.T.; MOURA, P. and AMARAJ COLLACO, M.T. Bacteroides spp. as alternative indicator organisms: monitoring through PCR 16S- rRNA amplification. In: OECD Workshop Molecular Methods for Safe Drinking Water, 1996, OECD Workshop Molecular For Safe Drinking Water.

McCRACKEN, V.J. and LORENZ, R.G. The gastrointestinal exosystem: a precarious alliance among epithelium, immunity and microbiota. Cellular Microbiology, January 2001, vol. 3, no. 1, p. 1-11.

MULLER, M. Mode of action of metronidazole on anaerobic bacteria and protozoa. Surgery, May 1983, vol. 93, no. 1 II, p. 165-171.

SALMINEN, S.; ISOLAURI, E. and ONNELA, L. Gut flora in normal and disordered states. Chemotherapy, 1995, vol. 41, no. 1, p. 5-15.

SCHWIERTZ, A.; LEHMANN, U.; JACOBASCH, G. and BLAUT, M. Influence of resistant starch on the SCFA production and cell counts of butyrate-producing Eubacterium spp. in the human intestine. Journal of Applied Microbiology, July 2002, vol. 93, no. 1, p. 157162.

SUAU, Antonia; BONNET, Régis; SUTREN, Malène; GODON, Jean-Jacques; GIBSON, Glenn R.; COLLINS, Matthew D. and DORÉ, Joel. Direct analysis of genes encoding 16S rRNA from complex communities reveals many novel molecular species within the human gut. Applied and Environmental Microbiology, November 1999, vol. 65 , no. 11 , p. $4799-4807$.

TANAKA, Junji; FUKUDA, Yoshihiro; SHINTANI, Shigeyuki; HORI, Kazutoshi; TOMITA, Toshihiko; OHKUSA, Toshifumi; MATSUMOTO, Takayuki and MIWA, Hiroto. Influence of antimicrobial treatment for 
Helicobacter pylori infection on the intestinal microflora in Japanese macaques. Journal of Medical Microbiology, March 2005, vol. 54, no. 3, p. 309-314.

WANG, R.F.; CAO, W.W. and CERNIGLIA, C.E. PCR detection and quantitation of predominant anaerobic bacteria in human and animal fecal samples. Applied and Environmental Microbiology, April 1996, vol. 62, no. 4, p. 1242-1247.

WANG, R.F.; KIM, S.-J.; ROBERTSON, L.H. and CERNIGLIA, C.E. Development of membrane-array method for the detection of human intestinal bacteria in fecal samples. Molecular and Cellular Probes, October 2002, vol. 16, no. 5, p. 341-350.

WILSON, M.J.; HALL, V.; BRAZIER, J. and LEWIS, M.A.O. Evaluation of a phenotypic scheme for the identification of 'butyrate-producing' Peptostreptococcus species. Journal of Medical Microbiology, August 2000, vol. 49 , no. 8 , p. 747-751.

WOESE, C.R. Bacterial evolution. Microbiological Reviews, June 1987, vol. 51, no. 2, p. 221-271.

YOUNG, Vincent B. and SCHMIDT, Thomas M. Antibiotic-associated diarrhea accompanied by large-scale alterations in the composition of the fecal microbiota. Journal of Clinical Microbiology, March 2004, vol. 42, no. 3, p. 1203-1206. 